\title{
Uma perspectiva sistêmico-discursiva sobre a mercantilização e a estratégia de gestão do ensino superior
}

\author{
A systemic-discursive perspective on commodification and higher education \\ management strategy \\ Una perspectiva discursiva sistémica sobre la mercantilización y la estrategia \\ de gestión de la educación superior
}

\author{
VICTOR LAUS-GOMES \\ ORCID iD: https://orcid.org/0000-0002-8497-4392 \\ Universidade Católica de Brasília.
}

RENATA ANDREONI

ORCID iD: https://orcid.org/0000-0002-7020-7133

Faculdade Instituto Brasileiro de Ciências Médicas Juscelino Jubitschek.

\begin{abstract}
Resumo: Resumo: O objetivo deste trabalho é analisar as escolhas discursivas do Grupo Estácio ao apresentar sua estratégia organizacional. Sob uma perspectiva sistêmico-discursiva, são discutidos os conceitos de sistema, sentido e comunicação. No contexto de expansão da educação privada evidenciam-se novas posturas e práticas educacionais e de gestão que privilegiam a visão de negócio e a mercantilização das relações. Termos e expressões que antes eram restritos ao sistema econômico, sob o código lucro/prejuízo, são incorporados e singularizados em uma semântica própria da estratégia educacional privada.
\end{abstract}

Palavras-chave: Gestão Educacional; Teoria dos Sistemas Sociais; Estratégia Organizacional; Semântica da Estratégia.

Abstract: The aim of this paper is to analyze the discursive choices of the Estácio Group when presenting its organizational strategy. From a systemic-discursive perspective, the concepts of system, meaning, and communication are discussed. In the context of private education expansion, new educational and management practices are evidenced. Terms and expressions that were previously restricted to the economic system, under the code profit/ Loss, are incorporated and singularized in a semantics proper to private educational strategy.

Keywords: Educational Management. Social Systems Theory. Organizational Strategy. Semantics of Strategy. 
Resumen: El objetivo de este trabajo es analizar las elecciones discursivas del Grupo Estácio al presentar su estrategia organizacional. Desde una perspectiva discursiva sistémica, se discuten los conceptos de sistema, significado y comunicación. En el contexto de la expansión de la educación privada, se evidencian nuevas actitudes y prácticas educativas y de gestión que enfatizan la visión empresarial y la comercialización de las relaciones. Los términos y expresiones que antes estaban restringidos al sistema económico, bajo el código de ganancias/ pérdidas, se incorporan y singularizan en una semántica propia de la estrategia educativa privada.

Palabras-clave: Gestión Educativa; Teoría de los Sistemas Sociales; Estrategia Organizacional; Semántica de la Estrategia.

\section{INTRODUÇÃO}

A chamada mercantilização do ensino superior parece ser uma realidade consolidada no Brasil. Uma evidência concreta é a abertura de capital de cinco grandes grupos educacionais na bolsa de valores. Sob uma perspectiva sistêmica, podemos afirmar, seguindo a hipótese de Andersen (2003b) sobre organizações polifônicas, que esses grupos materializam a eclosão das fronteiras e o imbricamento ou acoplamento entre os diferentes sistemas sociais, como o econômico, o educacional, o científico, o político e o jurídico, característica marcante das sociedades contemporâneas. Nesse sentido, as organizações educacionais podem ser compreendidas por meio de suas ligações simultâneas com os distintos sistemas funcionais.

Neste artigo $^{1}$, fazemos uma leitura dos sentidos sobre a estratégia construídos em textos institucionais do grupo Estácio. Nosso objetivo é compreender as escolhas discursivas da organização para apresentar sua estratégia e, com isso, constituir-se comunicativamente como Instituição de Educação Superior (IES). Entendemos que, por meio dessas escolhas, é possível distinguir-se dos demais sistemas sociais, incluindo outras organizações educativas, a sociedade e, especificamente, o sistema educacional e as políticas públicas para a educação superior.

Esta proposta é desenvolvida à luz do pensamento do sociólogo alemão Niklas Luhmann $(2016$; 2011). Ao compreender os sistemas sociais como instâncias constituídas fundamentalmente por comunicação, o autor fornece um quadro para pensarmos os fenômenos sociais a partir de suas impossibilidades, impermanências, imprevisibilidades, instabilidades e incertezas. Ou seja, fundamentalmente, de sua contingência, a partir das relações (re)estabelecidas.

1 Este trabalho apresenta parte dos resultados de projeto financiado pelo CNPq (Chamada Universal 2016). 
A comunicação, conceito central para a teoria de Luhmann, é uma operação essencialmente social, que origina, mantém e reproduz os sistemas sociais. Apesar de pressupor a relação entre duas ou mais consciências, ela não pode ser "imputada a nenhuma consciência isolada" (LUHMANN, 2011, p. 293) e sim, a sua própria dinâmica relacional, que depende da conexão entre diferentes acontecimentos comunicacionais. É, portanto, emergente e redundante. Para haver comunicação é preciso haver conexões entre diferentes acontecimentos, constituindo uma rede comunicacional que sustenta os sistemas sociais. Uma organização, sob essa perspectiva, pode ser compreendida como um sistema autopoiético de acontecimentos comunicacionais interconectados. Poderíamos dizer, nesse sentido, que a comunicação é responsável pela própria sustentabilidade das organizações. Ou seja, a ausência de comunicação inviabilizaria as organizações.

Sobre a perspectiva teórica de Luhmann, quando tratamos de práticas discursivas, a condensação de formas comunicacionais pode ser compreendida como um processo de produção de sentidos. O sentido, nesta concepção, é experimentado por sistemas de consciência e por sistemas de comunicação. Para o autor, não há vinculação obrigatória a um sujeito e o acesso ao mundo do sentido se dá através da distinção entre meio e forma. Os elementos do meio estão acoplados de modo amplo e os da forma, de modo estreito. Assim, podemos compreender os sentidos como condensações de formas em contextos de possibilidades. A parte interior da forma indica o sentido e a outra, o mais além, um campo aberto de alternativas. Como não há rigidez nessa distinção, o que é forma em um momento pode ser meio em outro. Um texto institucional é, portanto, meio e forma. Meio, para um conjunto de formas que podem ser condensadas em torno das práticas sustentáveis da organização, e forma, em meio a um conjunto de práticas comunicacionais que constituem as estratégias de comunicação da mesma organização.

Sistema, sentido e comunicação constituem, assim, a tríade conceitual sobre a qual propomos pensar a semântica da estratégia organizacional. Para o autor alemão, a semântica é caracterizada como a quantidade de formas generalizáveis de diferenças (por exemplo, conceitos, ideias, imagens e símbolos) disponíveis para a seleção de sentidos nos sistemas de comunicação. Essa multiplicidade de sentidos é capturada em novas formas (decisões), que se fazem disponíveis para decisões futuras e que constituem a essência da estratégia. Conforme Gomes (2016), a estratégia organizacional é formada em/por decisões que (re)produzem e sustentam as fronteiras sistêmicas das organizações, diferenciando-as de seus ambientes e (re)construindo suas identidades em um processo sistêmicocomunicacional. Com base nesses pressupostos e na atualização da noção de 
semântica proposta por Andersen (2011, 2003a), chegamos à semântica da estratégia - sentidos e formas generalizáveis sobre a estratégia organizacional (re)produzidos pelas organizações em seus movimentos de diferenciação sistêmica.

Diante desta compreensão teórica é que propomos tecer um debate crítico-reflexivo sobre as escolhas discursivas do Grupo Estácio e como elas configuram uma semântica de sua estratégia organizacional. Para tanto, inicialmente, realizamos uma breve explanação sobre o cenário contemporâneo da educação superior no Brasil, a fim de melhor contextualizar o âmbito no qual o Grupo está inserido. Em seguida, apresentamos a estratégia analítica e a discussão sobre a semântica da estratégia da Estácio.

\section{EDUCAÇÃO SUPERIOR NO BRASIL: CONSIDERAÇÕES SOBRE O CONTEXTO CONTEMPORÂNEO}

$\mathrm{O}$ advento dos grandes grupos empresariais da educação tem um marco importante no artigo 20 da Lei de Diretrizes e Bases da Educação Nacional LDB (BRASIL, 1996) em que foram caracterizadas as instituições particulares em sentido estrito, diferenciando-as daquelas de caráter comunitário, confessional e filantrópico. Recentemente, o referido artigo foi revogado pela lei no 13.868 de 2019, que classifica as instituições de ensino em públicas, privadas e comunitárias, eliminando a classificação de "particulares em sentido estrito" e a não finalidade de lucro das comunitárias, estabelecendo que privadas e comunitárias podem ser qualificadas como confessionais e/ou serem certificadas como filantrópicas.

Diferentes pesquisadores destacam a LDB/1996 como um movimento inicial da fragmentação e expansão do ensino superior no Brasil. Chaves (2010) desenvolve uma análise crítica sobre esse processo, na medida em que a lei passou a permitir, também, a dissociabilidade entre ensino, pesquisa e extensão, até então inseparáveis no escopo das universidades, como definição exposta na Constituição Federal de 1988. Conforme a autora, o ano de 2007 é outro marco à ampliação da educação superior, a partir da constituição de redes e fusões de instituições privadas - nacionais e internacionais - e pela abertura de seus capitais nas bolsas de valores. Esse processo é identificado por Chaves (2010) como formação de oligopólios, encadeando o impulsionamento da mercantilização do ensino superior. "A tese é de que o sistema de ensino superior deve se tornar mais diversificado e flexível, objetivando uma expansão com contenção nos gastos públicos" (CHAVES, 2010, p. 483).

Se, por um lado, esse movimento expansionista pode ser percebido como oportunidade de democratização do acesso ao ensino superior, por outro, é necessário problematizar os interesses envolvidos e seus possíveis impactos. 
(Re)Pensar as bases do desenvolvimento da educação superior é um processo complexo e, portanto, não se sustenta a partir de um pensamento uníssono. Há distintos entendimentos e interesses que entram em conflito na arena democrática para a efetivação das políticas educacionais. Nesse sentido, nossa intenção é contextualizar essa reforma, sob uma perspectiva crítica, trazendo à tona os diferentes elementos envolvidos na retórica desse processo, destacando seus diferentes fluxos e deslocamentos.

Ao destacarmos a década de 1990 como um marco inicial, é importante considerarmos os ideários do governo brasileiro na época, expressos no Plano Diretor da Reforma do Aparelho do Estado (PDRE), sob a presidência de Fernando Henrique Cardoso (Partido da Social Democracia Brasileira - PSDB), constituída por dois mandatos (1995-2002). O Plano, profundamente marcado pelas premissas de privatização e terceirização, indicava a diminuição da responsabilização direta do Estado em diferentes esferas e, por consequência, no ensino superior. O desenvolvimento e fortalecimento dessa política se sustenta nos anos subsequentes, com a criação de bolsas para estudantes do ensino superior privado, como o Programa Universidade para Todos (PROUNI), implementado a partir de 2005. A isenção fiscal proporcionada pela adesão ao Programa contribuiu para a redução de custos e rentabilidade das instituições participantes, além de uma maior atratividade e penetração junto a públicos/ mercados até então com difícil acesso ao ensino universitário. O PROUNI foi uma iniciativa da gestão do presidente Luís Inácio Lula da Silva (2003-2010), do Partido dos Trabalhadores - PT. Embora PSDB e PT sejam partidos políticos de orientações ideológicas distintas, a reforma expansionista do ensino superior se mantém. Faz-se importante, porém, considerar que:

[...] os anos 2000 caracterizam uma nova configuração do neoliberalismo no Brasil, implementado especialmente a partir dos governos de Lula da Silva (20032010) e de Dilma Rousseff (2011-2016), o qual consiste em combinar políticas econômicas de corte neoliberal com políticas sociais redistributivas de caráter compensatório, baseado em um consenso de que o sincretismo entre o Estado e o mercado seria a base para a restauração "estabilidade econômica" com "justiça social” (LÉDA; SOUSA, 2018, p. 156, grifos originais).

Nos diferentes momentos históricos, independentemente do governo, o que se evidencia, desde a década de 1990, é a expansão e o fortalecimento do neoliberalismo na educação do ensino superior. Outro exemplo importante desse processo é o Fundo de Financiamento Estudantil (FIES), instituído no governo FHC, em 2001, com o propósito de conceder financiamento aos estudantes de baixa renda para pagamento das mensalidades de curso superior no ensino privado. O FIES se manteve nos governos seguintes, com reformulações que 
permitiram a sua ampliação e consolidação até os dias atuais. A LDB, o PROUNI, o FIES, a Meta 12 do Plano Nacional de Educação (PNE) ${ }^{2}$, entre outras políticas, conformam um discurso de "democratização" do acesso ao ensino superior, ao mesmo tempo em que favorece e fortalece a criação e atuação de grupos privados no setor, em detrimento da educação pública. Não obstante as diferentes perspectivas ideológicas em relação às premissas de eficácia e eficiência sobre o ensino público e privado, o fato que destacamos é que tais conformações não são isentas de interesses e, portanto, são constituídas por sentidos, que vão se (des/re) configurando, conforme as intenções expressas (discursos), de maneira explícita e/ou implícita, e as relações estabelecidas. Diante do exposto, destacamos que o posicionamento contemporâneo das instituições privadas de ensino superior está permeado por esses movimentos, que não alheios, influenciam e perpassam a semântica da estratégia de cada IES que se encontra neste contexto.

\section{PERCURSO METODOLÓGICO}

Nosso percurso analítico é construído com base na análise semântica proposta por Niels Andersen (2011, 2003a), a partir da teoria sistêmica de Niklas Luhmann. Andersen é um pesquisador dinamarquês do departamento de Gestão, Política e Filosofia da Copenhagen Business School, com estudos sobre gestão e bem-estar social sob a perspectiva da teoria sistêmica, da história conceitual, da teoria do discurso e da desconstrução conceitual. Ao propor a análise semântica, delineia uma possibilidade de operacionalização da teoria sistêmica de Luhmann, construída, essencialmente, para compreender a sociedade, a constituição e as transformações dos sistemas sociais. No caso do autor alemão, o interesse recai sobre a diferenciação funcional da sociedade e sobre como os sistemas sociais se constituem em/por comunicação, originando estruturas semânticas que fundamentam sua constituição, operação e transformação. Andersen (2011, 2003a) desenha um percurso analítico em que a aparente rigidez da teoria sistêmica é flexibilizada para a compreensão dos processos contemporâneos de produção de sentidos, especificamente aqueles relacionados à gestão pública e privada. A seguir, discutimos os principais conceitos e reflexões que compõem esta estratégia analítica.

2 Aprovada em 2014, a meta 12 do plano propõe "elevar a taxa bruta de matrícula na educação superior para 50\% e a taxa líquida para 33\% da população de 18 a 24 anos. Assegurada a qualidade da oferta e expansão para, pelo menos, $40 \%$ das nova matrículas na rede pública" (http://pne.mec.gov.br/videos/item/71pne-meta-12). 
A análise semântica é orientada pela distinção entre semântica e sentido, privilegiando a formação e a condensação do sentido em um número de conceitos que, juntos, formam uma reserva semântica que é colocada à disposição para a comunicação. A ênfase está, portanto, na condensação de sentidos e no horizonte de formas generalizáveis que ela implica. Luhmann define sentido como a unidade da distinção atualidade/potencialidade. Algo se apresenta como central para o pensamento ou para a comunicação, em um determinado momento. Este algo é atualizado em relação a um horizonte de atualizações possíveis. Há sempre um núcleo cercado por outras potencialidades, que não podem ser utilizadas ao mesmo tempo. Conforme Luhmann (2016, P. 81):

O fenômeno do sentido aparece sob a forma de um excedente de remissões a outras possibilidades do vivenciar e do agir. Algo está no foco, no centro da intenção, e outra coisa é indicada marginalmente como horizonte para um e-assim-por-diante do vivenciar e agir.

Potencialidades ou possibilidades não podem ser compreendidas apenas como uma estrutura que precede a atualização, mas, também, como um horizonte de expectativas que emergem a partir dela. Sentido é a apresentação simultânea de realidade e potencialidade. O sentido "não é algo substancial, nem fenomenológico, e tampouco tem uma unidade quantitativa. De certo modo, ele é apenas uma espécie de diferença entre meio e forma" (LUHMANN, 2011, p. 235). Ele é formado por uma operação, pensamento ou comunicação, que desaparece instantaneamente. Por isso, precisa ser criado recursivamente e sempre emerge em referência a outro sentido.

A semântica, por sua vez, expressa formas de sentido condensadas e generalizáveis que são disponibilizadas para operações comunicacionais. Essas formas são relativamente dependentes de situações específicas e obtém seu conteúdo a partir da comunicação que as seleciona. Essencialmente, a busca recai sobre conceitos. Estes são condensados e generalizados com base em uma multiplicidade de sentidos e expectativas. Assim, a utilização de um conceito estabelece determinadas expectativas para a continuidade de uma comunicação. Além disso, o conceito é genérico, isto é, não é idêntico em todas as situações e depende do contexto. A multiplicidade de sentidos em um conceito está relacionada à distinção conceito/contra-conceito. Não pode haver um conceito sem um contra-conceito que impõe restrições ao primeiro. A observação desta oposição, e de como ela se constitui ao longo do tempo, pode ser considerada uma das fases da estratégia analítica proposta por Andersen (2011; 2003a). Assim como a experiência de sentido nos sistemas sociais e nas consciências individuais é construída por meio da observação de uma distinção fundamental entre o atual 
e o potencial, a estratégia analítica fundamenta-se na observação como operação básica da compreensão. A análise semântica aplica o historicismo como uma maneira de observar e descrever a reserva conceitual atual, mobilizando questões sobre como os sentidos e as expectativas são formados; e sobre como eles são condensados e generalizados em conceitos que estabelecem reservas conceituais para determinados sistemas de comunicação.

Para Luhmann $(2016$; 2011), há três dimensões de sentido que podem ser decompostas e, no movimento de análise, de acordo com Andersen (2011), podem ser aplicadas na/para a observação das mudanças semânticas: a dimensão material, a dimensão temporal e a dimensão social. A primeira, material ou factual, remete à distinção básica da estrutura de observação, ou seja, "isto" e "aquilo", partindo de uma escolha de "objetos de intenção constituída de sentido (em sistemas psíquicos) ou temas de comunicação constituída de sentido (em sistemas sociais). Na perspectiva sistêmica, importa observar como são criadas "indicações manejáveis para se lidar com referências do mundo" (LUHMANN, 2016, p.100) e como as oposições isto/aquilo (ou dentro e fora da forma) são construídas. A semântica da temporalidade trata da forma que observamos e definimos o passado e o futuro. O futuro é um horizonte de expectativas, o passado, um espaço de experiências, e o presente existe como uma tensão entre os dois. Sob essa perspectiva, podemos compreender o tempo como uma continuidade movente, promotor de heterogeneidades qualitativas. A partir do tempo, direcionamos nossas ações, na medida em que o presente se ocupa de espacializar a temporalidade, em atos, expressões e significados, produzindo inteligibilidade à vida. A dimensão social, em termos de semântica, é uma questão de formas generalizadas de distinção entre "nós" e "eles". Identidades sociais são a unidade de distinção entre nós e eles. A dimensão social diz respeito a semântica da construção das identidades, em que elas só podem ser "nós" (conceito) em relação a eles (contra-conceito). Não há "nós" a não ser em comparação a "eles". "Eles" só existem, por sua vez, em "nosso" discurso sobre "eles". Isto significa que expectativas sobre os "outros" criam a fronteira para expectativas sobre "nós". Não há semântica que não construa formas factuais, sociais e temporais. Após reunir o material a ser analisado, é possível iniciar a análise pela leitura dos textos com um olhar sobre como eles estabelecem as distinções entre "passado" e "futuro" e entre "nós" e "eles". Podem ser construídos quadros para cada texto, para destacar a valorização de "futuro" em detrimento do "passado" e, dessa forma, delinear um "tempo analítico", já que as mudanças conceituais serão identificadas. A análise não se resume aos quadros, mas eles podem ser um recurso para iniciar a observação das mudanças semânticas. As relações nós/ eles e passado/futuro podem ser compreendidas como relações entre conceitos/ 
contra-conceitos e podem fundamentar as questões sobre os deslocamentos conceituais. Dessa forma, não se trata apenas de uma questão sobre como "nós" e "eles" são valorizados no tempo, mas sobre as tensões entre eles (ANDERSEN, 2011).

Andersen (2011) se refere ao estudo de semânticas contemporâneas como, por exemplo, a semântica da sustentabilidade e a da cidadania, e chama a atenção para as incertezas que podem surgir ao considerarmos esses objetos como conceitos, isto é, formas generalizadas, ou como formas em desenvolvimento, que emergem por meio da generalização. Para o autor, a tensão entre singularidade e generalidade possibilita a observação da maneira como as generalidades podem ser ligadas a condições específicas e vice-versa. Ou seja, sobre como o particular é tratado universalmente e como determinadas ideias tidas como universais definem o que pode aparecer como singular. O conceito de sustentabilidade, por exemplo, condensa sentidos e adquire qualidades universais, ao mesmo tempo em que define condições singulares para a discussão sobre meio-ambiente e questões sociais na comunicação organizacional. É justamente nesta tensão entre singularidade e generalidade que propomos o estudo da semântica da estratégia.

Andersen (2011) destaca que o enfoque de Luhmann, ao discutir as semânticas sociais, recaiu sobre as histórias dos sistemas funcionais (educacional, legal, político, entre outros) e sobre como elas foram construídas ao longo de centenas de anos. Quando propõe sua estratégia analítica, o pesquisador dinamarquês privilegia semânticas contemporâneas e indica uma possibilidade de observação do processo de condensação de sentido por meio da distinção entre três níveis de condensação e generalização: conceitos vazios, semântica e normas.

O conceito vazio é o nível mais baixo de condensação de sentidos e expectativas. Pode ser considerado, conforme o autor, um conceito específico com um contra-conceito inespecífico. Um conceito vazio como a sustentabilidade, em meados dos anos 1980, cria a possibilidade para diversas tentativas de especificar o que não poderia ser considerado sustentável. No nível da semântica, não há somente a criação de um conceito individual, mas de uma reserva conceitual que fica disponível para a comunicação e que constrói um espaço de possibilidades que inclui expectativas generalizadas sobre as dimensões material, temporal e social. As normas, no último nível, delineiam expectativas específicas quando, por exemplo, uma semântica é transformada em um conjunto de prescrições que restringe práticas e, de maneira conformista, desqualifica os desvios.

Neste trabalho, consideramos que a abordagem proposta por Andersen (2011, 2003a) indica um caminho possível para a investigação das estratégias organizacionais e, mais especificamente, para a discussão sobre como as instituições de ensino privadas constroem seus discursos estratégicos e constituem- 
se comunicativamente em um contexto em que predomina o gerencialismo, ou estado gerencial, a instrumentalização do saber e a expansão do setor da educação privada.

\section{A SEMÂNTICA DA ESTRATÉGIA DO GRUPO ESTÁCIO}

O grupo Estácio iniciou suas atividades em 1970, quando foi criada a Faculdade de Direito Estácio de Sá na Zona Norte do Rio de Janeiro. Desde então, vem ampliando sua atuação, ofertando novos cursos em diversas modalidades e expandindo sua presença em todos os estados brasileiros. Em 2005, ano de implementação do PROUNI, deixa de ser uma sociedade civil filantrópica e se torna uma sociedade civil com fins lucrativos. Ao abrir seu capital na bolsa de valores, em 2007, consolida sua proposta empresarial. No ano de 2019, de acordo com seu site institucional (ESTÁCIO, 2019), possui, em seu quadro de funcionários, mais de oito mil professores e cinco mil administrativos, noventa unidades (49 faculdades credenciadas e 11 centros universitários), e pode ser considerada a segunda maior empresa de educação do país, com mais de 500 mil alunos.

Com o objetivo de refletir sobre as escolhas discursivas da Estácio e de compreender a semântica da estratégia configurada em seus textos institucionais, selecionamos, no site institucional da empresa (ESTÁCIO, 2019), uma declaração sobre os princípios de sua estratégia disponível na seção "Investidores" e a "Mensagem do Presidente" incluída no Relatório de Sustentabilidade de 2018.

$\mathrm{Na}$ leitura dos princípios da estratégia, emergem conceitos relacionados à estratégia taiscomoinovação, qualidade, marketing, cultura organizacional, expansão e novos negócios, ganhos e rentabilidade. Se pensarmos em níveis de condensação e generalização em torno desses conceitos, percebemos uma reserva semântica fortemente associada à prática gerencial. São conceitos presentes no discurso empresarial e poderiam compor declarações sobre estratégia em organizações dos mais diversos setores de atuação. A semântica da estratégia, ou seja, a reserva de sentidos construída em discursos sobre negócios, é mobilizada e (re)produzida no discurso da Estácio. Suas particularidades e apropriações reforçam e indicam a relação sistêmico-discursiva entre os discursos organizacionais, que poderia, em outras abordagens (FREIRE, 2014), ser compreendida como o interdiscurso ou a memória discursiva. Inovar, para o grupo educacional, é monitorar o mercado e renovar seu portfólio de produtos. Nesse sentido, procura manter a oferta de cursos alinhada às necessidades de mercado e às tendências de desenvolvimento econômico das regiões onde atua, além de ampliar a oferta de cursos e de lançar novidades em cursos livres de curta duração, cursos preparatórios para concursos 
e de especialização. A qualidade é associada à diferenciação e a uma "educação de primeira linha", que encaminha os alunos para o mercado de trabalho, promove "atendimento de alto padrão" e a "experiência do aluno junto à Companhia". O marketing fortalece a regionalização das mensagens e o reconhecimento da marca em cada região. Com relação à cultura organizacional, há uma aproximação ao conceito de "modelo de gestão", reforçando aspectos como a gestão profissionalizada, a meritocracia, a atração, promoção, treinamento e retenção de talentos, a transparência e o crescimento sustentável com rentabilidade. Portanto, uma cultura evidentemente gerencial. A expansão e os novos negócios privilegiam os investimentos na educação à distância, cursos de pós-graduação lato sensu, cursos preparatórios para concursos e o segmento de educação corporativa. Entre os conceitos mobilizados para apresentar sua estratégia, ainda estão os ganhos de eficiência e a rentabilidade, que manifestam a preocupação com os mecanismos de arrecadação e cobrança, bem como com a gestão de custos e decisões que promovem os ganhos de margem, ou seja, favorecimento de disciplinas a distância e oferta de turmas de estudo dirigido.

O Relatório de Sustentabilidade do Grupo Estácio é formulado, assim como pela maioria das empresas com capital negociado na bolsa de valores, de acordo com as diretrizes da GRI (Global Reporting Initiative), uma organização não governamental fundada em 1997. Inicialmente, era um projeto da ONG norte-americana CERES (Coalition for Environmentally Responsible Economies) e, posteriormente, se aliou ao Programa das Nações Unidas para o Meio Ambiente (PUNUMA). Em 2002, tornou-se uma organização independente sediada em Amsterdã. Hoje, tem parcerias com a OCDE, o Pacto Global e a ISO 26000. O objetivo da GRI é criar diretrizes para que as organizações possam relatar informações sobre sua atuação em relação ao ambiente, à sociedade, ao seu desempenho econômico-financeiro e a suas práticas de governança corporativa, para ajudar os investidores a tomarem decisões fundamentadas. Em 2013, a GRI lançou a versão G4 de suas diretrizes, com maior rigor técnico relacionado, por exemplo, a temas anticorrupção e a emissões de energia, questões atuais sobre sustentabilidade e direitos humanos, de acordo com os princípios da ONU (TERREO, 2019).

Mesmo tendo sua origem na definição de padrões de comunicação relacionados à gestão da sustentabilidade, as normas da GRI envolvem, em suas versões atualizadas, além das dimensões sociais e ambientais, aspectos da estratégia e da gestão, bem como do desempenho econômico, financeiro e de mercado. Conforme as diretrizes da GRI (2013), a seção do relatório reservada para a mensagem da administração deve apresentar uma declaração do principal executivo sobre a relevância da sustentabilidade para a organização, as tendências, 
os resultados e as prioridades estratégicas da organização. Com a abrangência do conteúdo do relatório recomendado pela GRI e sua validação por entidades nacionais e internacionais, o formato foi adotado por grandes empresas, substituindo os antigos relatórios de gestão, que não seguiam um padrão prédeterminado.

No Relatório de Sustentabilidade de 2018, o presidente Eduardo Parente é apresentado como executivo com experiência adquirida no comando de grandes empresas brasileiras. Em forma de entrevista, são respondidas seis questões e a ênfase recai sobre o "papel de inserção social" da Estácio, ao conseguir "levar conhecimento a muitas pessoas que não tinham a oportunidade de cursar uma universidade pública". Entre os diferenciais da instituição, destaca a identificação com as demandas do mercado e um "espírito pragmático, voltado a tornar melhor a vida das pessoas”. A gestão de custos, sem a perda do padrão de qualidade, é a forma de viabilizar o acesso dos estudantes e de expandir a atuação da empresa. Quando se refere à qualidade, afirma, se referindo aos professores, que o "corpo acadêmico é a 'cola' que mantém a Estácio unida". O relacionamento com os alunos é tratado como "transmissão de conhecimento" e como "experiência do estudante", que pode ser melhorada com base no investimento em engajamento e em uma "cultura que coloque o aluno no centro de tudo", por meio do cuidado com o atendimento e com "as demandas de cada um". Para o futuro, o caminho é a expansão da educação a distância, o investimento em tecnologia mobile, para que as pessoas possam estudar no ônibus e no trem, a abertura de novos cursos e novas Unidades e as aquisições, de maneira que outras instituições possam se beneficiar do sistema e dos valores da Estácio.

É possível perceber, nos textos analisados, a utilização de conceitos, ou seja, formas de sentido condensadas e generalizáveis, comuns a empresas de diferentes segmentos de atuação, tais como inovação, marketing, gestão de custos e experiência do cliente, afastando o discurso da Estácio do que poderíamos entender como condições singulares do contexto educacional. Em detrimento de aspectos relacionados, por exemplo, às práticas de ensino-aprendizagem, às metodologias e ambientes de aprendizagem, ao incentivo à pesquisa e à extensão, ganham espaço as reduções de custos, os ganhos de rentabilidade e as estratégias mercadológicas.

Ao enfatizar a importância da qualidade do ensino, no texto publicado em seu site institucional, singulariza o sentido, se referindo à qualificação do corpo docente e aos benefícios que oferece a esses profissionais, "como plano de saúde e seguro de vida, patrocínios para produção científica e programas de formação stricto sensu, e programas de remuneração variável para aqueles que se destacam nas suas áreas". Alude, ainda, aos resultados obtidos no ENADE. Na mensagem 
do presidente, não há menções a iniciativas para qualificação de docentes ou a avaliações de aprendizagem, apesar de haver referência ao professor como a "cola que mantém a Estácio unida”.

A lógica expansionista da educação superior, evidenciada nas novas formas de organização acadêmica e nas políticas de financiamento da educação superior privada, é singularizada no "papel de inserção social" da Estácio, em sua atuação junto a um público com dificuldades para acessar o ensino superior, em seu dito "espírito pragmático" e também em sua estratégia de expansão, privilegiando a educação a distância. Configura-se, dessa forma, a tensão entre singularidade e generalidade, a semântica da estratégia de uma instituição privada de ensino superior, com fins lucrativos, que assume sua condição polifônica em relações sistêmicas de acoplamento entre as lógicas/sistemas/discursos econômico, educacional, legal e político.

A declaração da missão institucional do Grupo, no texto do site, indica a dimensão material e a distinção sistêmica básica da organização: "Integramos academia e gestão para oferecer uma educação transformadora ao maior número de pessoas, criando impacto positivo para a sociedade". A integração proposta reflete o acoplamento sistêmico entre educação e economia, entre escola e negócios. Esta é a distinção fundamental porque configura uma fronteira que, ao definir a gestão como missão, considerada sob a ótica do lucro e dos negócios, exclui tudo aquilo que pode comprometer essa natureza. Esta seria, sob a perspectiva sistêmica, a estrutura básica de observação do sistema Estácio.

A semântica da construção identitária, ou a dimensão social, proposta pela teoria sistêmica, é revelada na caracterização do "modelo de ensino" e do "modelo de gestão", reforçando a distinção fundamental e a autorreferencialidade sistêmica:

Nosso modelo de ensino é coordenado por uma equipe acadêmica central
altamente capacitada, que atua em conjunto com milhares de professores
conteudistas do Brasil todo, que assim constroem nossos currículos de modo
coletivo, em linha com uma tendência global já em curso em países desenvolvidos.
Por isso, os currículos dos nossos cursos são nacionalmente integrados,
atualizados às demandas do mercado de trabalho e seguem os pré-requisitos
regulatórios estabelecidos pelo MEC" (ESTÁCIO, 2019).

Nosso modelo de gestão é orientado para resultados e focado na busca de qualidade do ensino oferecido aos nossos alunos, em sincronia com a busca de maior rentabilidade e resultados positivos para a empresa." (ESTÁCIO, 2019).

Ao declarar "nosso modelo de ensino" e "nosso modelo de gestão", particulariza e distingue sua operação de outras organizações do setor, valorizando sua postura gerencialista, o atendimento às demandas do mercado e a orientação 
para resultados. Por um lado, singulariza o conceito de "modelo de gestão" referindo-se à qualidade da oferta de ensino para os alunos, embora seu discurso evidencie a materialização da relação de acoplamento e de adesão aos pressupostos e aos códigos de sentido do sistema econômico e de negócios.

A dimensão temporal da semântica da estratégia do Grupo é configurada ao delinear um horizonte de expectativas e projetos de expansão revelados em elementos textuais como as "novas oportunidades de negócio", "a perpetuação da cultura organizacional e do nosso modelo de gestão" e na fala do presidente da empresa: "[...] Só assim poderemos crescer ainda mais, levar todas essas coisas boas que fazemos para mais gente". Nos textos analisados, as referências ao passado não são muitas e se limitam a reforçar e legitimar as escolhas presentes, relacionadas aos modelos de ensino e de gestão e aos projetos futuros, mencionando o sucesso em avaliações de ensino e os resultados alcançados em anos anteriores.

\section{CONSIDERAÇÕES FINAIS}

No contexto de expansão da educação privada, evidenciam-se novas posturas e práticas educacionais e de gestão que privilegiam a visão de negócio e a mercantilização das relações, em que alunos se tornam clientes e, as instituições de ensino, empresas ou companhias (termo utilizado pelo Grupo Estácio em seus textos institucionais). Esta é uma realidade que deverá pautar as decisões das organizações do setor, nos próximos anos. Os discursos produzidos sob essas condições materializam as tensões e constituem um espaço diferenciado para o estudo da gestão educacional, revelando as relações sistêmicas de acoplamento, as perturbações ou irritações (LUHMANN, 2016, 2011), a (re)produção de sentidos e de uma semântica própria de gestão e estratégia do ensino superior privado.

Essa semântica, ou reserva conceitual, define um conjunto de expectativas sobre os sentidos e também sobre as práticas empreendidas por essas organizações. Sob a perspectiva sistêmico-discursiva, são (re)construídos núcleos de sentido que constituem os horizontes de possibilidades para a operação desses sistemas organizacionais, caracterizando e reforçando padrões. Assim, termos/expressões que antes eram restritos ao sistema econômico, sob o código lucro/prejuízo, são incorporados e singularizados em uma semântica própria da estratégia educacional privada. É o caso, por exemplo, do marketing, da experiência do cliente e do modelo de gestão.

Atentar para a construção semântica envolvida na proposta de comunicabilidade do Grupo Estácio evidencia mudanças sobre os sentidos atribuídos à educação. A reforma da educação, neste caso, não passa por um projeto específico, mas por um conjunto de ações sobre os quais percebemos a 
prevalência do enfoque gerencial e dos interesses mercadológicos. As dimensões atribuídas à educação são (re)tecidas por um discurso financeirizado, privilegiando pressupostos quantitativos, na medida em que passa a ser um ativo exponencial do sistema econômico.

A aplicação da teoria sistêmica para a compreensão da gestão educacional de instituições privadas indica novas possibilidades de estudos. Entre elas, destacamos os processos de formulação e implementação de políticas públicas voltadas para a educação superior em relação aos acoplamentos e interações entre os diferentes sistemas sociais envolvidos, bem como as diferentes semânticas (re) produzidas em práticas dos/nos diversos níveis de gestão da educação superior.

\section{REFERÊNCIAS}

ANDERSEN, Niels A. Discursive analytical strategies: understanding Foucault, Koselleck, Laclau, Luhmann. Bristol: The Policy Press, 2003a.

ANDERSEN, Niels A. Polyphonic organisations. In: BAKKEN, Tore; HERNES, Tor. (Org.). Autopoietic organization theory: drawing on Niklas Luhmann's social system perspective. Copenhagen: Copenhagen Business School Press, 2003b.

ANDERSEN, Niels A. Conceptual history and the diagnostics of the present. Management and Organizational History, v. 6, n. 3, p. 248-267, 2011.

BRASIL. Lei n. 9.394, de 20 de dezembro de 1996 e atualizações - Lei de Diretrizes e Bases da Educação Nacional. Brasília, 1996. Disponível em: <http://www.planalto.gov.br/ccivil_03/leis/19394.htm>. Acesso em: 1 nov. 2019.

CHAVES, Vera L. J. Expansão da privatização/mercantilização do ensino superior brasileiro: a formação dos oligopólios. Educ. Soc., Campinas, v. 31, n. 111, p. 481-500, 2010.

ESTÁCIO. Site institucional. Disponível em: <http://portal.estacio.br/>. Acesso em: 19 out2019.

FREIRE, Sérgio. Análise de discurso: procedimentos metodológicos. São Paulo: Instituto Census, 2014. 
GOMES, Victor M. L. R. Uma leitura comunicacional da estratégia nas organizações. Galáxia, n. 33, p. 226-238, set.-dez., 2016.

GRI. G4: Diretrizes para relato de sustentabilidade. Amsterdã: Global Reporting Initiative, 2013. Disponível em: <http://www.b3.com.br/data/ files/F7/07/8C/C9/5B243510DF0CA135790D8AA8/GRI-G4-Manual-deImplementacao.pdf>. Acesso em: 9nov2019.

LÉDA, Denise B.; SOUSA, Ana Paula R. Políticas educacionais para o ensino superior de 2003 a 2012: expansão, precarização e privatização. Movimento Revista de Educação, Niterói, n. 8, p. 150-178, 2018.

LUHMANN, Niklas. Introdução à teoria dos sistemas. Petrópolis: Vozes, 2011.

LUHMANN, Niklas. Sistemas sociais: esboço de uma teoria geral. Petrópolis: Vozes, 2016.

TERREO, Glaucia. Entrevista: Glaucia Terreo, representante da Global Reporting Initiative no Brasil, fala sobre a evolução dos relatórios de sustentabilidade. [Entrevista concedida a] Karen Pegorari Silveira. Portal FIESP. Federação das Indústrias de São Paulo, São Paulo. Disponível em: <https://www.fiesp.com. $\mathrm{br} /$ indices-pesquisas-e-publicacoes/entrevista-glaucia-terreo-representante-daglobal-reporting-initiative-gri-no-brasil-fala-sobre-a-evolucao-dos-relatorios-desustentabilidade/>. Acesso em: 9nov2019.

\section{Victor Laus-Gomes}

Doutor em Comunicação Social pela PUCRS, Mestre em Administração pela Unisinos. Professor e pesquisador do Programa de Pós-Graduação em Educação e do Mestrado Profissional Inovação em Comunicação e Economia Criativa da Universidade Católica de Brasília. Líder do Núcleo de Estudos em Estratégia e Gestão Educacional (CNPq/UCB). Coordenador do Projeto "A comunicação organizacional e os discursos sobre a estratégia: um estudo em textos institucionais de grandes empresas brasileiras e em notícias sobre negócios" (Chamada Universal CNPq 2016).E-mail: victorlaus@gmail.com 


\section{Renata Andreoni}

Doutora em Comunicação Social pela PUCRS, com estágio doutoral na Université Paris-Sorbonne/Paris IV. Mestre em Comunicação Social pela PUCRS. Possui especialização em Gestão Cultural, Patrimonial e Turismo Sustentável pela Fundación Ortega y Gasset, Buenos Aires/ARG. Graduada em História pelo IPA. Professora e Coordenadora de Pós-Graduação Lato Sensu da Faculdade IBC. Membro do Núcleo de Estudos em Estratégia e Gestão Educacional (CNPq/UCB). E-mail: andreoni.renata@gmail.com

Recebido em 06 de janeiro de 2020. Aprovado em 09 de março de 2020. 